\title{
Editorial
}

Rev. Enf. Neurol. (Mex)

\section{LAS BUENAS PRÁCTICAS EDITORIALES EN LA PRODUCCIÓN Y DIFUSIÓN DEL CONOCIMIENTO EN ENFERMERÍA.}

\author{
.la ciencia que no se publica no existe \\ y lo que no se publica y se difunde no es ciencia. \\ Informe APEI 2013
}

Cada vez es más claro para quienes formamos parte de los grupos de trabajo de enfermería la necesidad (e incluso obligatoriedad) de la difusión, apropiación y aplicación del conocimiento producido por las y los propias/os enfermeras/os.

De manera particular, la difusión toma importancia a partir de la segunda década del siglo XX cuando, en 1952, se publica en Estados Unidos de Norteamérica la primera revista de investigación en enfermería, Nursing Research, ${ }^{2}$ y años más tarde la Revista Latino-Americana de Enfermería (Rev. Latino-Am. Enfermagem) la cual ve la luz por primera vez en el año 19933. Esta última se ha convertido, en el ámbito Latinoamericano e Iberoamericano, en una importante vía para que el personal de enfermería de a conocer la producción de conocimiento.

Para el caso de México las aún escasas revistas de enfermería de carácter científico que existen se han congregado, desde hace algunos años, en torno a un grupo de trabajo denominado Red Mexicana de Editores de Revistas Científicas de Enfermería (Red MERCE), el cual ha sido la base para el desarrollo conjunto; buscando alcanzar estándares de calidad, sustentados en buenas prácticas editoriales, que posibiliten un conocimiento publicado válido y confiable, para la toma de decisiones del profesional de enfermería dentro y fuera de nuestro país. ${ }^{4}$

Acorde con el Committee on Publication Ethics (COPE), 5 la honestidad intelectual debe ser alentada activamente en todos los cursos de estudio médicos y científicos, de igual manera la ética en la publicación a fin de evitar y saber que hacer cuando hubiere mala conducta editorial...

En una breve reflexión alrededor de este planteamiento, podemos darnos cuenta de que no es suficiente con querer publicar sino que, para hacerlo, es necesario conocer y seguir una serie de recomendaciones que, idealmente, los propios editores de las revistas deben difundir a través de diferentes medios (en sus normas de publicación, en sus políticas editoriales, dentro de su propia página web, etc.) y que atañen a los involucrados, a lo largo del proceso editorial, (autores, revisores y editores) su cumplimiento.

Es importante señalar que cuando una persona presenta un manuscrito para su evaluación, y posible publicación, éste representa prácticamente el final del proceso investigativo (qué se pretendía alcanzar, cómo se llevó a cabo y cuáles fueron sus resultados y conclusiones) y, lo que se evalúa de forma prioritaria es el cumplimiento de estándares metodológicos, acorde al diseño y tipo de estudio, así como el del respeto a la ética que debió haberse seguido en todo el estudio. Es contradictorio pues la mayoría de estos aspectos están sustentados y dan cuenta del trabajo realizado desde el inicio hasta el final del mismo.

En cuanto a las recomendaciones para autores, revisores y editores, éstas habitualmente se van actualizando. De manera general incluyen aspectos relativos a; autoría, diseño del estudio y aprobación ética, análisis de datos, conflicto de intereses, el proceso de revisión por pares (peer review), publicación redundante, plagio, deberes de los editores, relaciones con los medios, publicidad y cómo tratar con la mala conducta (si la hubiere) en los involucrados así como cuáles son las directrices a seguir para enviar un manuscrito para su evaluación y posible publicación en una revista. ${ }^{5.6}$

Dado el avance de la enfermería en los diferentes ámbitos de ejercicio profesional, podemos afirmar hoy día que nada nos excluye como autores, revisores o editores e incluso, como lectores, de conocer y aplicar las pautas de buenas prácticas 
que debemos seguir para la producción y difusión de un conocimiento válido y confiable pues, como ya se comentó, en múltiples ocasiones éste va a ser la base para la toma de decisiones en los diferentes escenarios donde desarrolla su labor el personal de enfermería.

Tomando en cuenta todo lo ya señalado, las editoras y editores de las Revistas Científicas de nuestro país deben asumir la responsabilidad de cumplir, y hacer cumplir, los lineamiento y estándares nacionales e internacionales en materia de publicación ya que, las publicaciones científicas tienen un papel preponderante y significativo donde la ética y los valores se transforman en la clave de su calidad ${ }^{7}$ lo cual, a su vez, es la base para la responsabilidad social de estas publicaciones. Lo anterior, sin perder de vista también el arduo trabajo que implica la dinámica operativa y estratégica de investigadores, autores de las publicaciones, árbitros, equipo de asistentes, revisores expertos, consejo científico de la revista, equipo editor, además de los organismos - instancias proveedoras del financiamiento y de los diferentes indices que evalúan las revistas con su clasificación establecida, sin olvidar el trabajo editorial de montaje e impresión?

De esta manera la labor de los editores de revistas, sustentada en los paradigmas de calidad y ética, requiere de la participación consciente y decidida de todos los implicados para una mayor y mejor producción y difusión del conocimiento en enfermería.

Mtra. Reyna Matus Miranda Profesor de Carrera Asociado C

ENEO - UNAM

\section{REFERENCIAS BIBLIOGRÁFICAS}

1. Baiget, T., Torres-Salinas D. Informe APEl sobre publicación en revistas científicas. Gijón: Asociación Profesional de Especialistas en Información. pdf 2013. Disponible en: https://goo.gl/uJ9tp2

2. Nursing Research. sitio oficial. Disponible en http://bit.ly/2y7ES4Z

3. Revista Latino-Americana de Enfermagem. Sitio oficial. http://bit.ly/2iCA4O3

4. Matus-Miranda R. La Red Mexicana de Editores de Revistas Científicas de Enfermería y su responsabilidad en la difusión del conocimiento. Rev Enferm Inst Mex Seguro Soc. 2017:25(4):241-3. Disponible en http://bit.ly/2yM8rZc
5. Committee on Publication Ethics (COPE). Directrices sobre buena práctica de publicación, 1999. http://bitly/2lyoQLs

6. INTERNACIONAL COMMITTE Of MEDICAL JOURNAL EDITOR (ICMJE) Recommendations for the Conduct, Reporting, Ediling, and Publication of Scholarly Work in Medical Journals. Updated December 2076. hittp://bit.ly/7UiMDZz

7. García GBC. Ética y valores en la responsabilidad social universitaria desde las publicaciones científicas. Visión de conjunto desde Multiciencias. Multiciencias. 2013; 13(3): 227-228. Disponible en: http://bit.ly/2yj3mZ6

\section{9} MMN Why Enf Neurol Vol. 16. No. 3 septiembre - diciembre 2017 